\title{
LOS NOMBRES DE OFICIOS DEL ÁMBITO MINEROMETALÚRGICO EN LOS SIGLOS DE ORO
}

\section{NAMES OF OCCUPATIONS IN THE FIELDS OF MINING AND METALLURGY IN THE 16TH AND 17TH CENTURIES}

\author{
María Teresa Cantillo Nieves \\ Universidad de Salamanca \\ mtcantillo@gmail.com
}

\begin{abstract}
RESUMEN
AbStraCt

La consolidación del castellano como vehículo de divulgación científica se hace patente en la España del siglo xvi con la publicación de una amplia serie de tratados técnicos que reflejan, junto a los avances tecnológicos de la época, un notable incremento del léxico que los componen. Los autores de estos tratados, para expresar conceptos anteriormente comunicados sobre todo en latín, o incorporar a su tecnolecto la denominación de nuevas realidades de origen americano, han de recurrir a métodos diversos, como el préstamo de términos ya existentes o la creación directa de unos tecnicismos específicos en castellano.

Algunas de las técnicas practicadas en este período son la metalurgia y la minería, cuyos avances y vocabulario específico se recogen en obras como De re metallica (1568), de Bernardo Pérez de Vargas, el Quilatador de la plata, oro y piedras (1572), de Juan de Arphe, el Diccionario y maneras de hablar que se usan en las minas (1609-11), de García de Llanos o el Arte de los metales (1640), de Álvaro Alonso Barba. En ellas, junto a las denominaciones de metales y minerales, sus técnicas de extracción y beneficio o instrumentos utilizados, encontramos numerosas voces con que se designan los diferentes oficios relacionados con ambas artes.

Nuestro propósito es dar cuenta de estos términos, que sobrepasan la cincuentena, con los que se nombraban a los trabajadores de las minas y a los encargados de la fundición y labrado de metales y minerales, algunos de los cuales se documentan en estos textos por vez primera. A continuación, los clasificaremos en función de los procedimientos morfológicos de formación que operan en ellos y de las técnicas de adaptación al castellano que han

The consolidation of Spanish as a vehicle for scientific communication is evidenced in 16th century Spain by the publication of a wide range of technical treaties that reflect, together with the advances in technology of the era, a notable increase in lexical variety.

In order to express concepts previously communicated prominently in Latin, or to incorporate into their technical jargon new terms of American origin, the authors of these treaties had to resort to a variety of lexical methods such as lexical borrowings or the creation anew of technical terms in Spanish.

Fields that saw notable advances during this period include metallurgy and mining, where advances and associated vocabulary are present in works like De re metallica (1568), by Bernardo Pérez de Vargas, Quilatador de la plata, oro y piedras (1572), by Juan de Arphe, Diccionario y maneras de hablar que se usan en las minas (1609-11), by García de Llanos, and Arte de los metales (1640), by Álvaro Alonso Barba. In these works, along with names of metals, minerals, tools and methods used for their extraction and smelting, one can find numerous words used to designate the various professions and trades related to both fields.

Our goal is to provide an account of these terms, over fifty of them, used to refer to mine workers and those in charge of casting and metalworking. Some of these occupations are documented for the first time in these texts. In the following, we classify these terms according to the morphological processes of word formation that originated them, and also according to the methods of adaptation to Spanish when borrowed from other languages, particularly Native American languages.
\end{abstract} experimentado tras tomarse en préstamo de otras lenguas, especialmente las indígenas con las que entran en contacto.
Keywords: specialized vocabulary, historical lexicography, language contact, history of metallurgy, history of mining 


\section{INTRODUCCIÓN}

El punto de partida para la elaboración de este trabajo es el desconocimiento de importantes parcelas de la historia del léxico de especialidad en lengua castellana. El español renacentista cuenta, sin embargo, con todo un repertorio de tratados técnicos relativos a diferentes ámbitos escritos en romance - frente al uso exclusivo que se había hecho en épocas anteriores del latín, del griego o del árabe como lenguas de cultura-, a través de los cuales podemos estudiar no solamente los conocimientos científicos y técnicos que se tienen en este período, sino el vocabulario específico de cada una de las áreas técnicas que se cultivan. Pretendemos, por tanto, completar los trabajos que, actualmente, tienen como objetivo dar a conocer la terminología científica existente en el español del siglo XVI, mediante la recogida y análisis de los tecnicismos presentes en obras representativas de unas áreas concretas, en nuestro caso, la metalurgia y la minería, que conforman el corpus textual que presentaremos a continuación.

$\mathrm{El}$ interés de estas dos áreas especializadas reside en que, con el descubrimiento de América y la explotación de sus recursos, se asiste no solamente a la incorporación de las técnicas americanas artesanales sobre extracción y beneficio de metales y minerales a las ya conocidas por los mineros y artífices europeos, más industrializados, sino a una sustancial ampliación del tecnolecto que estos emplean. Este se enriquece con el vocabulario relativo a estas técnicas o procesos, pero también con el referido a otros campos muy diversos, como el de los metales y minerales propios de aquellas tierras, las herramientas o instrumentos utilizados o las denominaciones de las diferentes tipologías de trabajadores que los extraen, manipulan o transportan para, posteriormente, someterlos a tratamiento metalúrgico.

En este contexto percibimos cómo, en la configuración de su nomenclatura en romance, se recurre no solo al préstamo de términos del ámbito minerometalúrgico que tienen su origen etimológico en las lenguas clásicas, o a la formación de nuevos términos utilizando los diferentes mecanismos, tanto morfológicos como semánticos, de los que dispone la lengua castellana para la constitución de su vocabulario, sino que se produce toda una eclosión de vocablos procedentes de las lenguas indígenas - especialmente, el quechua y el aimara- que, o bien competirán en el uso con 
sinónimos procedentes de la tradición europea anterior, o bien darán nombre a las nuevas realidades que se conocen en territorio americano.

Nuestra hipótesis de trabajo es, por tanto, que el contacto lingǘstico que tiene lugar en los asientos mineros, donde se reúnen operarios de muy diversa procedencia geográfica, produce un notable incremento terminológico, ya que conlleva la convivencia de los términos aportados por los europeos, muchas veces reservados a los oficios de mayor cualificación, con otros con origen etimológico en las lenguas americanas, en el caso de ser contribuciones de los trabajadores nativos de aquellas tierras.

Para comprobarlo, hemos extraído el vocabulario técnico presente en unos textos concretos redactados en romance en los Siglos de Oro, que se convierten en fuentes imprescindibles para documentar y estudiar la terminología metalúrgica y minera de esta época. Estos textos son De re metallica (Madrid, 1568), de Bernardo Pérez de Vargas; el Quilatador de la plata, oro y piedras (Valladolid, 1572), de Juan de Arphe y Villafañe; la Historia natural y moral de las Indias (Sevilla, 1590), de José Acosta ${ }^{1}$; el Libro general de las reduciones de plata y oro (Lima, 1597), de Joan de Belveder y, ya de la primera mitad del siglo XVII, el Arte de los metales (Madrid, 1640), de Álvaro Alonso Barba. A estos tratados o manuales se añade un repertorio lexicográfico manuscrito que es especialmente rico en vocablos mineros, el Diccionario y maneras de bablar que se usan en las minas, compuesto en territorio americano entre 1609 y 1611 por el minero y veedor de origen castellano García de Llanos².

En estas obras encontramos numerosas voces, algo más de una cincuentena, con las que se denominaban a los diferentes trabajadores de las minas y a los encargados de la fundición y labrado de metales y minerales, algunas de las cuales se documentan

\footnotetext{
${ }^{1}$ En este caso hemos utilizado exclusivamente el libro IV de la obra, que se centra en describir los metales y minerales, junto con otros elementos del medio natural, que el Padre Acosta encuentra en el Nuevo Mundo.

${ }^{2}$ Este corpus de trabajo, que constituye el núcleo del que tomamos nuestros ejemplos, se complementa con otras obras técnicas del mismo período también compendiadas en Mancho y Quirós (2005) y que suponen la fuente del Diccionario de la Ciencia y de la Técnica del Renacimiento (DICTER), marco de investigación en el que se inscribe este artículo. Son especialmente recurrentes, en el caso de las denominaciones de oficios, las documentaciones extraídas del Reportorio de todas las premáticas de Hugo de Celso (1553), al legislarse en él multitud de aspectos relacionados con las diferentes actividades profesionales.
} 
en estos textos por primera vez en lengua castellana. El análisis de este conjunto de términos referidos a las profesiones u oficios nos permitirá hacer una clasificación y un estudio de los mismos en función de su procedencia etimológica o de los procedimientos endógenos de formación que operan en ellos.

\section{LOS NOMBRES DE OFICIOS EN ESTOS T'RATADOS}

Clasificar e intentar sistematizar los procedimientos de formación que intervienen en el conjunto de tecnicismos documentados en un corpus representativo cobra, indudablemente, una importancia especial en los estudios que analizan el léxico desde una perspectiva histórica, ya que el conocimiento de la etimología de cada término, junto a la comprensión de los formantes empleados en su construcción, pueden resultarnos de gran ayuda a la hora definir de una manera no solo precisa, sino también metódica, unas voces especializadas que, en muchas ocasiones, no han llegado a figurar en los diccionarios académicos, o no con estas acepciones ${ }^{3}$.

En estos casos, establecer los significados de algunos de los tecnicismos mediante el recurso a las definiciones expresadas por los propios autores en sus obras, como sucede en apiri ${ }^{4}$, o a las relaciones semánticas que se descubren, por ejemplo, gracias a los sinónimos ofrecidos en el propio texto para esclarecer determinados conceptos,

\footnotetext{
3 Algunos autores, como Alonso González (2003), Mancho, Herráez, Cantillo y Carriazo (2004) o Camacho Niño (2014), han estudiado la recepción de tecnicismos áureos de diferentes ámbitos en diversas obras de la tradición lexicográfica española y han podido constatar la ausencia de un número considerable de los mismos en los repertorios generales. Alonso González (2003, p. 61-62) certifica que algunos de los términos mineros documentados en obras científicas y literarias "nunca encontraron su espacio en la Academia; otros gozaron de un efímero paso por sus páginas; otros fueron recogidos con acepciones que no responden al sentido con que las usaron los autores que hemos revisado". También Camacho Niño (2014), quien se ha ocupado de rastrear, precisamente, la presencia de las voces especializadas de la metalurgia y de la minería que figuran en la Historia natural del Padre Acosta en diccionarios académicos y otros textos de diferentes épocas, comprueba la falta de documentación de algunos de estos términos en los repertorios de la Corporación, si bien detecta una presencia especialmente significativa en el caso específico de los tecnicismos que figuran en la obra de este autor, al haber sido empleada como fuente para el Diccionario de Autoridades.

4 "Dícense comúnmente apiris los indios que van de un pueblo a otro con algunas cargas de los pasajeros, y en las minas son los indios que se ocupan en sacar el metal que otros barretean o juntan en la mina a la haz de la tierra" (Llanos, ca. 1609-11, p. 8-9).
} 


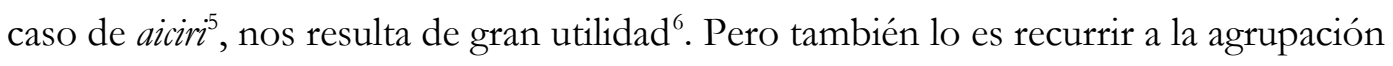
de los términos por familias léxicas, ya que, una vez establecido el sentido de la base léxica de la que parte el conjunto de vocablos que las forman, podemos comprender y delimitar la significación de cada uno de sus integrantes atendiendo a los mecanismos de morfogénesis que operan en ellos, lo que reviste especial importancia en el caso de algunas de las voces menos conocidas ${ }^{7}$.

Aplicado a los nombres de oficios que nos ocupan, es frecuente que, junto a las denominaciones de herramientas o instrumentos, encontremos, derivadas de ellas, las designaciones de las técnicas en que se emplean, las cuales, a su vez, originan el sustantivo con que aludimos a la profesión de quien las realiza, ejerce o usa. Así, del indigenismo guaira, referido al horno usado por los indios para fundir minerales aprovechando la fuerza del viento, deriva ya en castellano la forma verbal guairar, esto es, la acción de beneficiar el mineral utilizando dicho horno, de donde, a su vez, resulta guairador, o experto, por tanto, en el beneficio de minerales mediante la guaira ${ }^{8}$.

El estudio y la clasificación de todos estos datos hacen que podamos ordenar también semánticamente este tipo de léxico, lo que, en el caso de las profesiones, se aplicaría fundamentalmente a la estructuración o división de las tareas atendiendo, sobre todo, al grado de conocimiento profesional o cualificado que se requiere para ejercerlas. Esto nos permite extraer conclusiones no solo de carácter etimológico y morfológico, sino que también, a la vista de la variedad de posibilidades combinatorias

\footnotetext{
5 "Los indios barreteros o ayciris que trabajan dentro en las minas, por maravilla lo hacen solos, sino acompañándose de dos en dos para ayudarse mejor y llevar más cómodamente el trabajo remudándose" (Llanos, ca. 1609-11, p. 21).

${ }^{6}$ Mancho Duque (2017, p. 547-548) detalla la frecuencia con la que, para aclarar conceptos que resultan a un tiempo novedosos y oscuros en castellano, se recurre en la prosa científica renacentista a "glosas explicativas para los términos, a los que se les proporcionaba, a veces, equivalentes en la lengua estándar [...]. Del mismo modo se utilizan estructuras léxicas bimembres de carácter sinonímico, los conocidos como dobletes léxicos, formados por dos elementos conectados mediante la conjunción $y$, o la $o$. En algunas circunstancias la adición del segundo podría deberse a una finalidad divulgativa, para hacer más comprensible el primero, representado bien por un término culto o vocablo novedoso".

7 "Los procedimientos endógenos de creación léxica pertenecen de lleno al estudio etimológico, pues constituyen modos de explicar el origen de palabras así como métodos de aproximarse a la motivación de los signos lingüísticos, ya que, aunque el significado sea arbitrario, el sentido de los derivados y compuestos resulta en cierto modo motivado para los hablantes, que pueden deducir los valores significativos de las palabras a partir de sus formantes o morfemas" (Carriazo, 2014, p. 149-150).

${ }^{8}$ El hecho de documentar tecnicismos formados ya con sufijos castellanos a partir de una base americana es muestra, además, del asentamiento del préstamo en nuestro idioma.
} 
de los mecanismos formativos observados, nos conduce a intuir una cierta jerarquización entre los trabajadores a partir de la lengua que emplean ${ }^{9}$, lo cual nos ayuda asimismo a ofrecer una visión histórica de la sociedad minera americana desde el punto de vista lingüístico.

\section{PROCEDIMIENTOS MORFOLÓGICOS DE CREACIÓN LÉXICA}

Tal y como hemos señalado en trabajos anteriores,

Los diferentes procedimientos gramaticales de creación léxica suponen una importante fuente de recursos tanto a la hora de generar nuevos tecnicismos, como de reconocer el posible significado de algún término desconocido para nosotros, ya que el hecho de que dispongamos de una serie de formantes productivos asociados a un significado resuelve en gran medida la dificultad de dar nombre a realidades que no se habituaban a emplear en castellano (Cantillo Nieves, 2010, p. 9495).

En efecto, uno de los mecanismos empleados con mayor profusión en las obras que componen nuestro corpus en la formación de los nombres técnicos de oficios es la derivación, es decir, la creación de un neologismo mediante la adición de afijos a otra palabra ya existente. A este proceso formal se unen otros, si bien son utilizados en menor medida, como la composición, ya sea propia, es decir, la unión de dos bases léxicas para formar un nuevo lema, o sintagmática, como se denomina la unidad pluriverbal cuyos componentes se coordinan para plasmar, de una manera gráfica, el concepto que pretenden representar.

A continuación, detallaremos los mecanismos más recurrentes a la hora de establecer los nombres relativos a los oficios o profesiones en estos tratados.

\footnotetext{
${ }^{9}$ Muysken (2017, p. 104), quien ha estudiado el multilingüismo que se dio en las minas de Potosí en la época colonial desde la perspectiva de la sociolingüística histórica, afirma que "surge con evidencia de las fuentes que existía una clara jerarquía entre las lenguas indígenas en la mina. Podemos formular la hipótesis de que esta jerarquía se correspondía con las principales divisiones de trabajo en la mina:

$\begin{array}{ll}\text { Quechua } & \text { Barreteros } \\ \text { Aimara } & \text { Apiris } \\ \text { Uru } & \text { Palliris }\end{array}$

Tal vez los yanaconas eran sobre todo quechua hablantes, y los mitas, aimara hablantes. En términos absolutos, la gran mayoría de los trabajadores en Potosí deben haber sido aimaras". Según este autor, el quechua podría haber servido como lengua intermediaria entre el castellano y otras lenguas americanas.
} 


\subsection{DERIVACIÓN POR SUFIJACIÓN}

La derivación es uno de los sistemas más productivos de los que dispone la lengua en general para la creación neológica. Es especialmente relevante como mecanismo en la formación de palabras dentro del lenguaje científico, por una parte, debido a que la paulatina homogeneización de dicho sistema a lo largo de la historia contribuye a dotar a este lenguaje de la claridad y precisión que lo caracterizan y, por otra, porque el cambio categorial que conlleva con frecuencia la adición de un sufijo a una base léxica nos permite que, sin que haya un cambio del significado conceptual, se pueda, por ejemplo, "pasar de un verbo [...] al nombre de acción correspondiente" (Lerat, 1997, p. 73).

En consonancia con estos rasgos, la derivación, especialmente la sufijación, es el procedimiento de construcción de tecnicismos que hemos podido localizar como mayoritario en el conjunto de textos que integran nuestro corpus, ya sea en las lenguas de las que se toman en préstamo, como veremos, o bien en términos formados directamente en castellano ${ }^{10}$.

\subsection{1. - dor}

El afijo -dor, procedente del sufijo latino con el que designamos nomina agentis -tor, -öris (Pharies, 2002, p. 169), se halla muy presente en la nomenclatura minerometalúrgica formada por derivación, siendo el morfema agentivo más documentado en estas obras, con una veintena de ocurrencias en total. Generalmente, se añade a bases verbales para la designación de nombres de oficios en los que se especifica el trabajo o labor que cada artífice desarrolla o en el que es experto, aunque también hemos podido documentarlo en un número considerable de ocasiones con otros usos habituales en español, entre otros, para la designación de herramientas e instrumentos diversos ${ }^{11}$.

Así, como nombres que aluden a las diferentes categorías de expertos en el tratamiento metalúrgico de los minerales hemos podido documentar afinador ${ }^{12}$,

\footnotetext{
${ }^{10}$ En este sentido, Almela (1999, p. 72) considera la sufijación el procedimiento más prolífico en la generación de neologismos, especialmente relevante al establecer una relación dinámica no solo formal, sino semántica y funcional entre bases y sufijos.

${ }^{11}$ Valgan como ejemplos los términos acendrador, cargador o quilatador.

12 "Si el afinador siente que con difficultad se aparta la plata de los otros metales, y lo mesmo se entienda del oro, eche dentro de la cendra en el metal cobre y carbón molido” (Pérez de Vargas, 1568, fol. 134r).
} 
apartador ${ }^{13}$, beneficiador ${ }^{14}$, dorador ${ }^{15}$, ensayador ${ }^{16}$, fundidor ${ }^{17}$ o tirador $^{18}$, término con el que se denominaba al artífice que reducía a hilos el oro. Estos oficios, más arraigados en la tradición metalúrgica europea anterior, están presentes ya en los textos más antiguos de nuestro corpus, especialmente en el de Pérez de Vargas, con las excepciones de tirador, cuya única ocurrencia se da en Acosta, y beneficiador, neologismo solamente recogido por Alonso Barba para denominar al experto en la innovadora técnica del beneficio por azogue, muy rentable a la hora de extraer la plata de la amalgama, y que hasta esa época no se pone en práctica en suelo americano ${ }^{19}$.

Junto a estos términos se hallan una serie de tecnicismos con los que se alude a los oficios referidos a las tareas o actividades realizadas en las labores mineras, como los

\footnotetext{
13 "Deve el señor de la mina tener apartadores assalariados y lugares disputados donde los metales se aparten" (Pérez de Vargas, 1568, fol. 75v).

14 "Sepa conocer los metales, sus calidades y diferencias [...]; conozca las malezas que los acompañan y no ignore el modo de quitárselas, los accidentes del açogue y estilo ordinario de beneficiar [...], no se admita por beneficiador a ninguno que no sepa hazer bien, por lo menos, un ensaye menor por fuego de toda harina, antes de incorporar el caxón, para enterarse de la plata que tiene y saber con certidumbre y no acaso lo que deve sacarle, sin dexar de hazer diligencias hasta que lo consiga" (Alonso Barba, 1640, fol. 38v).

15 "Sus Altezas [...] defendieron que ningún platero, dorador, ni otra persona alguna dorasse ni plateasse sobre yerro, ni cobre, ni latón, espada, ni puñal, ni espuelas" (Celso, 1553, fol. CXIv).

16 "Ay otra manera de pesas entre plateros y ensayadores, las quales llaman pesas del dineral" (Pérez de Vargas, 1568, fol. 146v).

17 "Deve el fundidor tener cuydado de limpiar las escorias que se hizieren o cuajaren en la hornilla, y de tener siempre limpios los agujeros por donde corre el metal" (Pérez de Vargas, 1568, fol. 83v).

18 "Los batihojas y tiradores saben bien la fuerça del oro en dexarse tanto adelgazar y doblar sin quebrar jamás" (Acosta, 1590, p. 200).

${ }^{19}$ Su novedad se hace patente en la fecha de la primera datación que ofrece el CORDE para la acepción técnica, 1605, en la Descripción breve de toda la tierra del Perú, Tucumán, Río de la Platay Cbile, de Fray Reginaldo de Lizárraga, apenas unos años anterior al Arte de los metales.
} 
sinónimos buscador ${ }^{20}$ y cateador ${ }^{21}$, chacaneador ${ }^{22}$, descubridor ${ }^{23}$, llamador ${ }^{24}$, pallador ${ }^{25} \mathrm{o}$ repasador ${ }^{26}$. Con la excepción del primero -ya presente en Pérez de Vargas-, se documentan en los textos más tardíos de nuestro corpus, hecho que resulta lógico, al tener algunas de estas palabras su origen último en las lenguas indígenas, caso de chananeador o pallador, o hacer alusión a las novedosas técnicas de beneficio de minerales que se aplican en el Nuevo Mundo, como sucede en repasador.

En todos estos casos, la unión de este sufijo a una base verbal nos permite definir cada uno de los términos como la 'persona encargada de X los metales', esto es, de afinarlos, de apartarlos o separarlos, o de dorarlos, ensayarlos, fundirlos o tirarlos, respectivamente. De igual manera, en el caso de las voces referidas a las tareas mineras, denominan a las personas encargadas de buscar los minerales haciendo catas en los terrenos, de transportarlos, de buscar nuevas vetas, de derribarlas con el fin de evitar hundimientos o de buscar minerales aprovechables entre los desechos de las minas, en este orden.

Encontramos también en la nomenclatura minerometalúrgica algunas voces motivadas por la utilización de instrumentos o herramientas que caracterizan las

20 "Como las fuentes sean bocas y espiraderos de las venas de la tierra, estas deven primero los buscadores considerar, si a bueltas del agua sale algún grano de plata o oro, o de piedra de buena y rica condición” (Pérez de Vargas, 1568, fol. 57r).

21 "Ya queda advertido atrás que lo hagan assí los beneficiadores, y aquí lo encargo a todos los mineros que lo sepan, mayormente los que llaman cateadores, que se ocupan en buscar y descubrir minerales nuevos" (Alonso Barba, 1640, fol. 86v-87r).

22 Hemos documentado este término junto a su sinónimo chacana, que también deriva del verbo chacanear: "Los indios que sirven de arrieros se dicen chacanas o chacaneadores y el trajín chacaneo" (Llanos, ca. 160911, p. 32).

23 "Se debe advertir [...] cómo el descubridor elige su mina, a lo cual se añade que todos los estacados a él, aunque se les adjudican las minas o estacas que piden y las tienen, no saben determinadamente dónde caen, sino a poco más o menos, hasta que el descubridor señala dónde quiere su mina" (Llanos, ca. 160911, p. 47).

24 "Requiere esta manera de labrar indios mañosos y de ánimo, más que robustos y fuertes, aunque todo es bueno. Y se dicen los que se ocupan en esto ayciris o llamadores" (Llanos, ca. 1609-11, p. 7).

25 "Y lo que así se junta se dice pallaco, lo cual se vende por cargas para revolver con otros metales, y los indios que se ocupan en esto se dicen palladores" (Llanos, ca. 1609-11, p. 97).

26 "Se dicen estas vueltas que se da al metal repasos y repasar y los indios que lo hacen repasiris o repasadores, en que los hay también muy diestros, que no todos lo saben bien hacer" (Llanos, ca. 160911, p. 43). 
funciones de los expertos en su uso, como la ya mencionada guairador ${ }^{27}$, o tinador $^{28}$, con que se denomina al encargado de sacar los metales de los cajones y depositarlos junto a la tina para su posterior lavado.

En relación con los oficios de limpiar y pulir las monedas, así como de acuñarlas, hemos podido documentar los términos blanqueador ${ }^{29}$ y marcador $^{30}, \mathrm{y}$, vinculado con las labores propias del orfebre, entallador ${ }^{31}$, cuyas primeras dataciones en este corpus se registran, como vemos, en textos legales en que se delimitan sus figuras.

Por último, hemos localizado algunas voces que, más que de oficios o profesiones, podrían considerarse denominaciones de actividades a las que se dedicaban algunos de los habitantes de los asientos de minas, caso de mordedor ${ }^{32}$, con la que se designa al individuo que, sin ser minero, entraba a las minas para aprovechar los minerales que otros habían labrado, o rescatador ${ }^{33}$, es decir, la persona que compraba el metal hurtado en las labores mineras.

\subsection{2. - ero}

El segundo grupo en cuanto al número de términos que lo componen es el de los nombres de profesión creados mediante la adición a una base léxica del sufijo agentivo -ero, que, como señala Pharies (2002, p. 229), es muy productivo en la formación tanto

\footnotetext{
27 “'Sabido en el reyno del Pirú el descubrimiento de Potosí, luego acudieron muchos españoles [...] para tomar minas en él. Acudieron también gran cantidad de indios de diversas provincias y, especialmente, los guayradores de Porco" (Acosta, 1590, p. 209-210).

28 "Luego que el cajón para, [...] el día que se ha de lavar, sacan del cajón el metal los indios tinadores y, hecho barro como está, lo ponen amontonado junto a la tina de mano o lavadero donde se ha de lavar" (Llanos, ca. 1609-11, p. 67).

29 "La moneda de plata y vellón ansí labrada dévese dar al blanqueador para que blanquee a vista del ensayador" (Celso, 1553, fol. CCXXIr).

30 "En cada una de las dichas ciudades el concejo ponga [...] un mercader, el qual tenga cargo de concertar y affinar todos los marcos y pesas que en la tal ciudad hoviere con el marco y pesas que por la tal persona le fuere dado. Y el tal marcador ponga encima del marco la señal de la tal ciudad o villa donde se marcare, y encima de las otras pieças menudas ponga el tal mercader su señal y el tal marcador" (Celso, 1553, fol. CCLIXr).

31 "El entallador aya por sus derechos, de cada marco de oro, quatro maravedís; y del marco de plata o vellón, de cada uno d'ellos, dos maravedís" (Celso, 1553, fol. CCXXIv).

32 "mordedores: Nómbranse de esta manera algunos hombres en los asientos de minas, que, sin ser mineros, o entendiendo muy poco de este menester, se están siempre a la mira, y en habiendo algo de consideración, luego procuran entrada, $[\ldots]$ y con algunos indios que alquilan entran a gozar la parte que pueden de lo que otros han trabajado y descubierto" (Llanos, ca. 1609-11, p. 94).

33 "Sin estos rescatadores que tratan de comprar el metal hurtado, hay otros no menos perjudiciales, sino más" (Llanos, ca. 1609-11, p. 114-115).
} 
de adjetivos como de "sustantivos derivados a partir de radicales nominales, reflejo de -ärius, sufijo latino de función análoga".

En algunos de los casos, la base nominal a la que se une indica el material concreto con el que trabajan estos artífices, como se aprecia en calero $^{34}$, estañero $^{35}$, berrero $^{36}$, lamero $^{37}$ o platero $^{38}$. Este último término, profusamente documentado en nuestro corpus, convive con su sinónimo argenter $^{39}{ }^{9}$, mucho menos frecuente, que deriva, según el $D E C H$ (s. v. argento), de argento 'plata', a su vez tomado del latín argentum. La escasez de ocurrencias de este vocablo podría deberse al éxito de plata frente a argento, que el DECH (s. v.) describe como un "latinismo ocasional que no ha arraigado nunca" y cuyas documentaciones en nuestro corpus son, en efecto, muy limitadas, lo que habría provocado que otros integrantes de su familia léxica corrieran la misma suerte ${ }^{40}$.

\footnotetext{
${ }^{34}$ Alude este término no solamente a la persona que saca la piedra y la calcina en la caldera, sino también a la que vende la cal: "Porque los caleros, después de aver hecho el concierto de entregar la cal de piedra dura, [...] buscan piedras toscas y muy blandas, por ser fáciles de cozer y menos costosas de sacar de la cantera" (Rojas, 1598, fol. 91r).

35 "Se contienen algunos secretos particulares que pertenescen a los officios metállicos, assí como plateros, aurífices, herreros, estañeros y officiales de cobre" (Pérez de Vargas, 1568, fol. 148v).

36 "El officio del herrero tiene algunos secretos y los principales son cinco: el primero, temple; el segundo, suelda; el tercero, blandura o dureza; el quarto, gravar; el quinto, dar color de oro o plata y lustre" (Pérez de Vargas, 1568, fol. 173v).

37 "Las personas que tratan en lamas, sin tener otro beneficio de metal, se dicen lameros" (Llanos, ca. 1609-11, p. 66). Se refiere aquí Llanos al profesional que beneficia las lamas minerales, esto es, el "lodo de mineral muy molido, que se deposita en el fondo de los canales por donde corren las aguas que salen de los aparatos de trituración de las menas" (DLE).

38 "La natural es una piedra luzia que se funde de manera de açúcar candi o de sal gemma, la qual sirve para soldar los plateros el oro y plata" (Pérez de Vargas, 1568, fol. 47r). En la época, esta voz designa al artífice que labra la plata o el oro.

39 "Un cavallero pescuda a quatro argenteros que en quánto tiempo le farán una cadena de oro que pese 200 ducados" (Ortega, 1512, fol. 129v).

${ }^{40}$ Este fenómeno ya ha sido estudiado por Jiménez Ríos (2018, p. 64), quien defiende que "en la evolución diacrónica de voces relacionadas formalmente puede haber diferencias, pero también semejanzas, y si una voz es desusada, puede llevar a otras a que tengan esa consideración; y si deja de serlo, es decir, si la voz pasa a ser usual, las relacionadas con ella pueden seguir el mismo camino".
} 
Como sucede con - dor, el sufijo -ero se añade también a bases nominales que denotan la herramienta con la que se trabaja y que caracteriza a su usuario, caso de barretero ${ }^{41}$, o bien el producto que este fabrica, como vemos en candelero $^{42}$ o monedero ${ }^{43}$.

Por último, en los términos azoguero ${ }^{44}$ y minero ${ }^{45}$ señala al dueño de determinado tipo de instalaciones, o bien a la persona que trabaja en las mismas.

\subsubsection{Otros derivados por sufijación}

Existen otros ejemplos de sufijos menos recurrentes en la formación de este tipo de sustantivos, que por su escasez hemos agrupado en este apartado. Son los casos de ista, que se añade a la base nominal alquimia en alquimista $^{46}$; -ado, en estacado ${ }^{47} \mathrm{y}$, finalmente, $-e$, empleado como sustituto de la flexión verbal en contraste $^{48}$.

\subsection{DERIVACIÓN POR PREFIJACIÓN}

Pese a ser un procedimiento particularmente rentable en el lenguaje de la ciencia (Gutiérrez Rodilla 1998), que aparece cuando un formante modifica el significado de la base a la que se antepone sin implicar un cambio categorial, únicamente encontramos en nuestro corpus un término formado mediante la adición del prefijo reiterativo re-.

41 “barreteros: Los indios que labran en virgen, por ser el principal instrumento con que se hace la barreta, se dicen así, a diferencia de los apiris o sacadores" (Llanos, ca. 1609-11, p. 11).

42 "Después de haber servido en esta ocasión, compran los indios candeleros los cestos vacíos y deshechos, mojan el coxoro y acomodan en él las candelas que venden para el Cerro en forma de manojos que llaman maítos" (Llanos, ca. 1609-11, p. 24).

43 "Quando los Reyes en España ordenaron monedas de oro y plata, fueron de diversos pesos; y a esta causa, los monederos hizieron del marco otras maneras de tomines" (Arphe, 1572, fol. 3r).

44 "azogueros: Dícense así los que tienen ingenios en Potosí, por el azogue del beneficio" (Llanos, ca. 1609-11, p. 11).

${ }^{45}$ Con este término se nombraba no solamente a los trabajadores en las minas: "No consiste el ser minero en conocer cuantos metales de plata se le pueden a uno mostrar de diferentes minerales, [...] sino en saber muy bien labrar y reparar las minas y hacer otras cosas que no pertenecen a este lugar" (Llanos, ca. 1609-11, p. 76), sino también a sus dueños: "Se pone, assimismo, en el dicho almacén, por cuenta de Su Magestad, todo el azogue que, después de pagado el quinto, les queda a los mineros. Y Su Magestad les manda pagar por cada quintal al precio contenido en el assiento que con los dichos mineros se toma por los señores visorreyes y governadores d'estos reynos” (Belveder, 1597, fol. 185r).

46 “Avicena [...] determina que, assí como el médico [...] purga los malos humores y [...] da la salud, [...] el alchimista sabio, purgando las impuridades del súlphur y argento vivo de los metales y purificándolas con su arte, es possible que engendre nueva especie con total corrupción de los metales que purifica, reduziéndolos a la primera materia" (Pérez de Vargas, 1568, fol. 13v).

47 "Cuando se hace algún registro de veta, los que piden y toman minas en ella tras el descubridor se dice que toman estacas [...]. Y hacer esto llaman estacarse, y al que lo hace estacado" (Llanos, ca. 160911, p. 47).

48 "Para esto suelen y acostumbran los contrastes y personas que tratan metal tener unas agujas o puntas, que son por todas veynte y quatro de metales diversos, con que cotejan el oro o plata u otro qualquier metal" (Pérez de Vargas, 1568, fol. 140v-141r). 
Es el caso de remuda ${ }^{49}$, que denomina a aquellos trabajadores que dan el relevo a sus compañeros en las minas.

\subsection{COMPOSICIÓN}

Este procedimiento formal de creación léxica también está presente en los términos referidos a las profesiones que figuran en el corpus. A pesar de haber registrado un número mucho menor de casos de este tipo que de los derivados por sufijación, algunos de ellos revisten especial interés por la peculiar combinación de los lexemas que los forman.

\subsubsection{Composición propia}

Este mecanismo formal se emplea en batihoja $^{50}$, cuyo esquema de formación es de verbo más sustantivo - frecuentemente usado en la composición de palabras en general-, y que designa al fabricante de pan de oro o plata empleado para dorar o platear.

En el resto de términos constituidos mediante la adición de dos lexemas se refleja, de manera inequívoca, la fecunda convivencia entre los hablantes de la lengua castellana y de las lenguas indígenas utilizadas por los trabajadores de las minas anteriormente mencionada, ya que se crean términos mixtos en cuya composición interviene un vocablo romance junto a otro americano, aspecto ya señalado por Alonso González (2002, p. 32).

Es lo que sucede en algunas de las voces presentes en el Diccionario de García de Llanos, como candelacamayo ${ }^{51}$ o quintocamay $0^{52}$, donde a las palabras castellanas candela y

\footnotetext{
49 "Los indios de la mita nueva [...], como no se dan maña al trabajo de las minas es poco lo que hacen, y, de miedo del castigo, llevan consigo [...] otros que les ayuden, [...] a los cuales llaman ellos remudas" (Llanos, ca. 1609-11, p. 113).

50 "Los batihojas y tiradores saben bien la fuerça del oro en dexarse tanto adelgazar y doblar sin quebrar jamás" (Acosta, 1590, p. 200). Córdoba de la Llave (1988, p. 756) detalla el origen de este término: "La operación de reducir el metal a láminas de finísimas proporciones se conoce por el nombre de batir, porque se lleva a cabo mediante martilleo, de manera que los artesanos que la realizaban eran llamados, en el siglo XV, batidores de hoja de plata o de hoja de oro y, por contracción de esos términos, batihojas". ${ }^{51}$ Como vemos en el ejemplo, este vocablo es sinónimo del mencionado anteriormente candelero: "Úsanse candelas y son necesarias en las minas para poder labrar [...]. Los indios que las hacen se dicen candelacamayos, que quiere decir 'oficiales de hacer candelas' y también candeleros" (Llanos, ca. 1609-11, p. 16).

52 "quintocamayo: Es la mitad castellano y la otra de la general. Y quiere decir 'persona que tiene a cargo el cobrar quintos de algún socavón’, o los derechos que se pagan” (Llanos, ca. 1609-11, p. 10).
} 
quinto se une un indigenismo para denominar a los encargados o camayoc ${ }^{53}$ de fabricar las candelas y de cobrar los quintos en las minas, respectivamente.

También encontramos, en esta misma obra, el compuesto mozoruna ${ }^{54}$, donde al término español mozo se une la voz quechua runa 'persona' (González Holguín, 1608, s. v.) para referirse a los nuevos relevos en el trabajo minero.

\subsubsection{Composición sintagmática}

Únicamente hemos hallado dos casos de este procedimiento de formación en los nombres de oficios, y son las expresiones sinonímicas pallador de pella y pallador de la ribera, con las que se alude a los encargados de separar y recoger los minerales que lleva el agua tras el beneficio ${ }^{55}$.

\section{PROCEDENCIA ETIMOLÓGICA DE LOS TÉRMINOS}

Un número considerable de los nombres de profesión documentados en estas obras se incorporan al castellano tomados en préstamo de otras lenguas, junto a algunos ejemplos, escasos, de voces patrimoniales. Resulta interesante profundizar en el origen etimológico de los mismos con el fin de poderlos agrupar en función de la tradición en que se insertan.

\subsection{LATINISMOS}

La historia de la metalurgia en la Europa renacentista tiene en la figura del alemán Georgius Agricola, considerado el fundador de la mineralogía y del arte de los metales como ciencia, a su máximo representante. Su obra De re metallica, publicada en 1556 y redactada íntegramente en latín, como era habitual en la época para este tipo de tratados técnicos, es pionera en la descripción de los avances de la industria minera tal

\footnotetext{
${ }^{53}$ Según González Holguín (1608, s. v.), el quechua camayoc significa 'oficial o mayordomo, el que tiene a su cargo haciendas o alguna chacra'.

54 "Los indios principiantes en el trabajo de las minas se dicen mozorunas, de la palabra runa, que en la general significa 'hombre o indio', y mozo, de nuestro vulgar mal aplicado, de suerte que cuando llega la mita nueva al asiento que viene de sus pueblos [...] los indios que en ella vienen, que no han asistido otra vez, se dicen mozorunas, como decir "novicios o principiantes"' (Llanos, ca. 1609-11, p. 94).

55 "Sin las maneras de pallar referidas, hay otra en la ribera donde están los ingenios, que es andar en ella al rebusco del azogue y pella que se lleva el agua del beneficio cuando sale de las tinas [...]. Y hacen para el efecto pozuelos en que se va juntando y de ellos sacan la arena que se recoge y, lavándola en bateas, apartan el azogue y pella que se junta, y estos se dicen palladores de la ribera o de pella" (Llanos, ca. 1609-11, p. 98).
} 
y como se conocía en aquel entonces (Sánchez Gómez, 2017, p. 554). Este tratado, eminentemente práctico, sirve como fuente indiscutible a Pérez de Vargas, cuya obra homónima, publicada pocos años después, ha sido considerada por los historiadores de la ciencia como un mero plagio de su predecesora ${ }^{56}$. En cualquier caso, si tenemos en cuenta la influencia de la obra latina del metalúrgico alemán, no resulta extraño que en la nomenclatura empleada por Pérez de Vargas encontremos algunos tecnicismos de origen culto, tomados de la lengua latina sin apenas experimentar cambios en su paso al castellano.

En concreto, encontramos los cultismos artifice ${ }^{57}$, aurífice ${ }^{58}$, lapidario ${ }^{59}$ o metálico ${ }^{60}$, que aluden a las actividades profesionales de mayor tradición en estas artes, o que requieren de un grado más alto de conocimientos técnicos.

\subsection{Americanismos}

A mediados del siglo XVI, la Villa de Potosí se convierte en un centro minero clave en la economía colonial española. El constante contacto lingüístico que se produce entre los operarios de las minas, de muy diversa procedencia ${ }^{61}$, se evidencia no solo en el elevado número de tecnicismos de origen americano que se recogen en las obras del período áureo analizadas ${ }^{62}$, sino que se hace patente con la elaboración de un repertorio

\footnotetext{
56 Cabe destacar, de todas maneras, su valor como fuente de documentación de la terminología minerometalúrgica renacentista en lengua castellana, pese a los diversos errores de traducción e interpretación que en ocasiones contiene.

57 "El azero, aunque algunos dizen ser mineral y metal distincto y de especie differente que el hierro, paresce, por testimonio de los artífices y maestros que le tratan, no ser assí” (Pérez de Vargas, 1568, fol. $38 \mathrm{r})$.

58 "De los secretos que pertenescen al officio del platero y aurifice que labra oro y plata" (Pérez de Vargas, 1568, fol. 148v).

59 "Se suelen hazer, a lo menos, esmeraldas tan finas y duras que suelen engañar a diestros lapidarios" (Pérez de Vargas, 1568, fol. 161v).

60 "Deve conoscer [...] la necessidad que se deve tener en abrir y cavar la tierra de la mina; y todos los artificios y formas de ensayar viendo los metales y de aparejarlos como conviene para hazer la prueva d'ellos y fundición, porque de una manera se ha de ensayar el oro, de otra la plata, de otra el cobre [...]; de manera que el buen metállico se deve tener por un artífice que communica con muchas sciencias y artes" (Pérez de Vargas, 1568, fol. 50v-51r).

${ }^{61}$ Muysken (2017, p. 98) define esta villa como receptora de la migración de poblaciones de muy diversos idiomas nativos (amerindios, europeos y africanos), lo que la convertiría en un verdadero "hervidero multilingüe". También Puche (2019) hace alusión al continuo trasvase cultural y lingüístico en este enclave minero.

${ }^{62}$ En Cantillo Nieves (2008) estudiamos la abundante terminología de origen indígena presente en el Arte de los metales de Alonso Barba, que, en este autor, se emplea sobre todo para designar metales, minerales y diversos tipos de instrumentos artesanales utilizados para molerlos o ensayarlos.
} 
lexicográfico específico para dar cuenta de la terminología empleada en estas zonas. En él, García de Llanos, además de definir las voces "que se usan en las minas", proporciona información etimológica, diatécnica, diatópica y de uso sobre los términos compendiados, lo que resultaría de gran interés para el buen entendimiento entre estos trabajadores ${ }^{63}$.

Algunos de estos términos se toman en préstamo directamente de las lenguas indígenas, como chasqui ${ }^{64}$, minga ${ }^{65}$, mitayo ${ }^{66}$ o pongo ${ }^{67}$, pero otros prueban el crisol lingüístico en el que se transforma esta zona minera, ya que, en consonancia con lo que describe Muysken (2017, p. 105), localizamos términos mixtos formados gracias a la suma de elementos tomados de lenguas diferentes, en este caso, la adición del sufijo aimara -ri, agentivo equivalente al castellano -dor, a una base léxica bien quechua o bien castellana, lo que demuestra una vez más la experiencia multilingüe en las minas ${ }^{68}$.

\footnotetext{
${ }^{63}$ Para una ampliación de las características de este Diccionario, así como de la manera que tiene García de Llanos de presentar los americanismos en él recogidos, remitimos a los análisis realizados por Alonso González (2002) y Cantillo Nieves (2006).

64 “Chasqui quiere decir 'correo'. Úsase de estas maneras de hablar en las minas cuando suceden hundimientos o se ofrecen otras prisas semejantes y hay necesidad de sacar afuera mucho desmonte, piedra y tierra del hundimiento [...], y asimismo a veces la hay de entrar alguna piedra mejor y más acomodada que la que hay en aquella parte y otras cosas para ir reparando" (Llanos, ca. 1609-11, p. 33). 65 "mingas: Dícese de mincani, que en la general quiere decir 'alquilar', y así, los indios que se alquilan de su voluntad se dicen mingas" (Llanos, ca. 1609-11, p. 92).

60 "Mita en la general quiere decir 'vez', y así, indios de mita o mitayos (que es lo mismo) quiere decir 'indios que les cupo la vez de trabajar o servir en algún ministerio', aunque en los de Potosí no se usa el nombre de mitayos sino solamente para los que se dejan los días de fiesta en el Cerro a guardar el metal" (Llanos, ca. 1609-11, p. 93).

67 "pongos: Dícese de puncu, que en la general significa 'puerta y portero', y en las minas [...] se aplicó en Potosí a un indio que en cada una de ellas tenía a cargo la mina, labor y herramienta de cada dueño, y aun algunas tuvieron puerta y llave y, cuando menos, la había del buhío donde se guardaba el metal [...]. $\mathrm{Y}$, finalmente, hacían oficio de mayordomos, y por tenerlo todo en su poder, debajo de llave o sin ella, se les dio el nombre referido de pongos o porteros" (Llanos, ca. 1609-11, p. 106).

68 "Muchas prácticas deben haber sido bilingües, implicando mezcla de lenguas, sobre todo aimara, quechua y castellano. Hay que darse cuenta que las dos principales lenguas indígenas implicadas, el quechua y el aimara, tienen muchas estructuras en común y comparten bastantes palabras" (Muysken, 2017, p. 105).
} 
Algunas muestras de este fenómeno son aiciri ${ }^{69}$, apiri ${ }^{70}$, palliri $^{71}$, pirquiri ${ }^{72}$, repasiri ${ }^{73}$ - sinónimo del anteriormente comentado repasador- o serviri ${ }^{74}$, como se denomina al operario que sirve o echa el mineral en el ingenio para su molienda.

La abundancia de préstamos de origen indígena frente al menor número de latinismos detectados en este campo, más frecuentes en otros ámbitos científicos y técnicos de la época, como puede ser el matemático ${ }^{75}$, incide en la particularidad de este léxico y en su carácter eminentemente práctico, donde prima la comunicación entre sus usuarios ${ }^{76}$.

\subsection{PrÉstamos con otros orígenes ETTMOLÓgicos}

En este punto concreto hemos registrado únicamente un par de préstamos cuyo origen es diferente al de los demás; se trata del término capata ${ }^{77}$, tal vez tomado del occitano antiguo (DECH, s. v.) para designar a los encargados de las hornazas donde las barras de metal se reducían a planchas a partir de las cuales fabricar monedas, y del italianismo soldado $^{78}$ (DECH, s. v. sueldo), con el que se denomina al dueño de minas que no dispone de ingenios propios.

69 "Requiere esta manera de labrar indios mañosos y de ánimo, más que robustos y fuertes, aunque todo es bueno. Y se dicen los que se ocupan en esto ayciris o llamadores" (Llanos, ca. 1609-11, p. 7).

70 "Sírvense de ellas en las minas los indios apiris o sacadores, para ayudarse a sacar mejor el metal" (Llanos, ca. 1609-11, p. 7).

71 "La segunda manera de pallar es limpiar el metal en las canchas donde se pone luego que se saca de las minas [...], que es apartar lo malo y desecharlo [...], y los que hacen esto se dicen palliris, en que de ordinario se ocupan muchachos y algunos indios viejos" (Llanos, ca. 1609-11, p. 97).

72 "Los indios diestros de hacer estas pircas y reparos [...] se dicen pirquiris" (Llanos, ca. 1609-11, p. 101). 73 "Sin estos rescatadores que tratan de comprar el metal hurtado, hay otros no menos perjudiciales, sino más, que son los que rescatan pella de los indios repasiris y tinadores" (Llanos, ca. 1609-11, p. 114115).

74 "Y porque no hay invención para que el metal vaya cayendo como en los molinos, que cae el trigo de la tolva, están en cada cabeza de ingenio cinco indios echando siempre metal, que dicen serviris, los cuales se remudan asistiendo unos de día y otros de noche" (Llanos, ca. 1609-11, p. 116).

75 Remitimos al detallado análisis sobre la procedencia de las voces matemáticas renacentistas que hace Molina Sangüesa (2017, p. 77-106).

${ }^{76}$ Se configura de este modo "un lenguaje técnico vivo, porque el uso real es el que marca la creación de términos en el Cerro de Potosî” (Alonso González, 2002, p. 34).

77 "La moneda se dé a labrar a los capataces y officiales y obreros. [...] Los capataces y obreros no reciben oro, ni plata, ni vellón, salvo el que fuere pesado por el maestro de la balanças y por ante el escrivano de la dicha casa, y que sea marcado por el ensayador" (Celso, 1553, fol. CCXXv).

78 "soldados dueños de minas: Dícense de esta manera los que en Potosí tratan de labrar y beneficiar minas y metales y no tienen ingenios" (Llanos, ca. 1609-11, p. 118). 


\subsection{Palabras patrimoniales.}

Para finalizar este apartado, podemos añadir algunas voces patrimoniales en español, cuyo número es escaso en estas obras y que denotan alguna condición referida a la actividad minera. Estas son dobla ${ }^{79}$, es decir, la persona que realiza un turno de trabajo doble en las minas, compaña ${ }^{80}$ y labor ${ }^{81}$.

\section{CONCLUSIONES}

$\mathrm{El}$ análisis de los términos con los que se denominan las diferentes profesiones u oficios relacionados con la metalurgia y la minería en los Siglos de Oro en castellano nos permite extraer algunas conclusiones que podrían extrapolarse, en general, al léxico de estos ámbitos especializados del Renacimiento hispano.

En primer lugar, podemos certificar la capacidad de la lengua castellana para la construcción de tecnicismos mediante sus propios mecanismos de creación léxica.

Por una parte, encontramos diversos procedimientos morfológicos de formación de palabras, entre los cuales destaca la derivación por sufijación -especialmente representada con los agentivos -dory -ero-, junto a otros empleados en menor número, como la prefijación o la composición, que permiten cubrir las necesidades de los usuarios de este tecnolecto, quienes llegan a fusionar no solo bases léxicas castellanas, sino, directamente, indigenismos con términos españoles.

También es significativo el recurso al préstamo, ya que registramos no solo voces de raigambre culta, en el caso de las profesiones asociadas a la tradición científica anterior, que hunde sus raíces en la metalurgia europea y cuya literatura se redacta en latín, sino que hemos podido constatar, asimismo, cómo la lengua se nutre de términos de origen americano como resultado de la necesidad de comunicación que se evidencia en las minas, siendo prácticamente simbólicos, en nuestro caso, los nombres de profesiones de otra procedencia etimológica.

\footnotetext{
79 "Se dicen, asimismo, doblas los indios que, como primero se dijo, quedan de una semana para doblar la siguiente" (Llanos, ca. 1609-11, p. 43).

80 “compañas: Los indios barreteros o ayciris que trabajan dentro en las minas, por maravilla lo hacen solos [...]. Y así, a cada dos indios se dice una compaña, los cuales trabajan en un mismo suyo [...] sucediendo el uno al otro en el trabajo y no a la par" (Llanos, ca. 1609-11, p. 21).

81 "Todos los indios de un dueño que labran en una misma mina, que sean pocos o muchos, se dice labor" (Llanos, ca. 1609-11, p. 64).
} 
En relación con este punto, es interesante poner de relieve la particularidad que este tecnolecto presenta al configurarse en torno al contacto lingüístico producido en América. Además de documentar voces que se toman en préstamo del quechua o del aimara, descubrimos otras que combinan ambas lenguas en sus procesos de derivación, lo que da lugar a la creación de términos bilingües. Parece ponerse de relieve, al mismo tiempo, una posible jerarquía social a través de la jerarquía lingüística.

Por último, es interesante mencionar que el carácter novedoso de muchos de estos vocablos hace que una de las fuentes principales de los términos relativos a profesiones sea precisamente el Diccionario y maneras de hablar que se usan en las minas, de García de Llanos. Aunque también en el resto de autores que integran nuestro corpus se han contabilizado diversos sustantivos referidos a este campo, especialmente aquellos que designan las profesiones relacionadas con el tratamiento del metal, es en la obra de este minero donde se recoge un número mayor de denominaciones de oficios menos cualificados, a los que quedarían relegados los nativos de aquellas tierras. La convivencia entre hablantes de lenguas diversas en las labores mineras produciría, pues, la necesidad de dar a conocer el significado de estos neologismos de composición, en ocasiones, multilingüe, lo que entroncaría con toda una corriente renacentista de elaboración de glosarios especializados de diferentes ámbitos con los que se pretendía suplir las carencias terminológicas de sus usuarios ${ }^{82}$.

Todo esto prueba no solamente la capacidad de la lengua castellana para cubrir la totalidad de las parcelas lingüísticas de la ciencia y de la técnica renacentistas, sino la hábil selección que esta hace de todo tipo de mecanismos lingüísticos, y de los términos o formantes más significativos de las lenguas con las que entra en contacto, para dotar a los trabajadores de las minas de un vocabulario comprensible para todos.

82 Como señala Mancho Duque (2017, p. 550), “para facilitar la comprensión de los numerosos tecnicismos vernáculos que se acumulaban en las parcelas más heterogéneas del ámbito científico y técnico comenzaron a elaborarse repertorios monolingües, muy dependientes de determinados textos concretos, $[. .$.$] hasta desembocar en la creación de auténticos glosarios".$ 


\section{BIBLIOGRAFÍA}

\section{Fuentes primarias ${ }^{3}$}

Acosta, J. de (1590). Historia natural y moral de las Indias. Libro IV. Sevilla: Juan de León.

Alonso Barba, Á. (1640). Arte de los metales. Madrid: Imprenta del Reyno.

Arphe de Villafañe, J. de (1572). Quilatador de la plata, oro y piedras. Valladolid: Alonso y Diego Fernández de Córdova.

Belveder, J. de (1597). Libro general de la reduciones de plata y oro. Lima: Antonio Ricardo.

Llanos, G. de (mss. ca. 1609-11). Diccionario y maneras de hablar que usan en las minas. Edición de Ramiro Molina (1983). La Paz: Musef.

Pérez de Vargas, B. (1568). De re metallica. Madrid: Pierres Cosin.

\section{Fuentes secundarias}

Almela Pérez, R. (1999). Procedimientos de formación de palabras en español. Barcelona: Ariel.

Alonso González, A. (2002). El Diccionario y maneras de hablar que se usan en las minas de García de Llanos: el comienzo de la Terminología Minera en castellano. En M. Campos Souto y J. I. Pérez Pascual (Eds.), De historia de la lexicografía. La Coruña: Toxosoutos, pp. 23-36.

Alonso González, A. (2003). Si no lo cultivas, sácalo de la mina, Asclepio, LV/2, pp. 43-66.

Cantillo Nieves, M. ${ }^{a}$ T. (2006). Los americanismos en el Diccionario y maneras de hablar que se usan en las minas (1609), de García de Llanos. En M. Campos Souto, F. Córdoba Rodríguez y J. I. Pérez Pascual, América y el diccionario. Anexos de la Revista de Lexicografía, 2. La Coruña: Servicio de Publicaciones de la Universidad de La Coruña, pp. 21-30.

Cantillo Nieves, M. ${ }^{a}$ T. (2008). Terminología minera de origen americano en el Arte de los metales (1640), de Álvaro Alonso Barba. En D. Azorín Fernández et al. (Eds.), El diccionario como puente entre las lenguas y culturas del mundo. Actas del II Congreso Internacional de Lexicografía Hispánica. Alicante: Universidad de Alicante-Fundación Biblioteca Virtual Miguel de Cervantes. CD, pp. 628-632.

Cantillo Nieves, M. ${ }^{a}$ T. (2010). Procedimientos morfológicos de formación de tecnicismos en De Re Metallica (1568), de Bernardo Pérez de Vargas. En A. M. ${ }^{a}$ Medina Guerra (Coord.) y M. C. Ayala Castro (Ed.), Los diccionarios a través de la historia. Málaga: Servicio de Publicaciones de la Universidad de Málaga (Colección: Estudios y Ensayos), pp. 91-110.

Camacho Niño, J. (2014). La recepción textual y lexicográfica de los términos de la minería y de la metalurgia empleados en la Historia natural y moral de las Indias de J. de Acosta (1590). En C. Grande, L. Martín Aizpuru y S. Salicio Bravo (Coords.), Con una letra joven. Avances en el estudio de la historiografía e historia de la lengua española. Salamanca: Ediciones de la Universidad de Salamanca, pp. 215-222.

Carriazo Ruiz, J. R. (2014). Los indigenismos en el Diccionario crítico etimológico castellano e hispánico de Joan Corominas y José Antonio Pascual, Epos, XXX, pp. 147-160.

${ }^{83} \mathrm{El}$ acceso a estas obras se ha realizado a partir de Mancho y Quirós (2005). 
Celso, H. de (1553). Reportorio universal de todas las leyes d'estos reynos de Castilla. Medina del Campo: Juan María da Terranova y Jacome de Liarcari (imprenta de Francisco del Canto), comp. Andrés Martínez de Burgos. [consultado en Mancho y Quirós (2005)]

Córdoba de la Llave, R. (1988). Los batihojas y las técnicas de ornamentación en metal (siglos XV-XVI). En M. E. Piñero, N. García Tapia, L. Á. González Arroyo, M. Jalón, F. Muñoz e I. Vicente Maroto (Coords.), Estudios sobre la Historia de la Ciencia y de la Técnica. Valladolid: Junta de Castilla y León, pp. 755-772.

Corominas, J. y J. A. Pascual (1991[1980]). Diccionario crítico etimológico castellano e hispánico. Madrid: Gredos, $3^{\text {a }}$ reimpresión $(D E C H)$.

González Holguín, D. (1608). Vocabulario de la lengua general de todo el Perú, llamada lengua Qquichua, o del inca. Ciudad de los Reyes: Francisco del Canto.

Gutiérrez Rodilla, B. (1998). La ciencia empieza en la palabra. Análisis e historia del lenguaje científico. Barcelona: Península.

Jiménez Ríos, E. (2018). La marcación diacrónica de familias léxicas en el diccionario, Cuadernos del Instituto de Historia de la Lengua, 11, pp. 45-68.

Lerat, P. (1997). Las lenguas especializadas. Barcelona: Ariel.

Mancho Duque, M. J. (2017). El español en la divulgación científica y técnica del Renacimiento. En A. M. Bernal (Ed.), Modernidad de España: apertura europea e integración atlántica. Madrid: Marcial Pons, pp. 535-552.

Mancho Duque, M. ${ }^{a}$ J., Herráez, G., Cantillo, M. ${ }^{a}$ T. y J. R. Carriazo (2004). Léxico especializado y lexicografía del Renacimiento. En M. ${ }^{a}$ P. Battaner y J. DeCesaris (Eds.), De Lexicografia: Actes del I Symposium Internacional de Lexicografia (Barcelona, 16-18 de maig de 2002). Barcelona: IULA, Universitat Pompeu Fabra, pp. 503-546.

Mancho Duque, M. ${ }^{a}$ J. (Dir.) y M. Quirós (Coord.) (2005). La ciencia y la técnica en la época de Cervantes: textos e imágenes. CD. Salamanca: Ediciones Universidad de Salamanca.

Molina Sangüesa, I. (2017). Letras, números e incógnitas: estudio de las voces aritmético-algebraicas del Renacimiento. Madrid: Iberoamericana-Vervuert.

Muysken, P. (2017). Multilingüismo y lenguaje mezclado en las minas de Potosí (Bolivia), Lingüística, 33/2, pp. 97-104 [en línea] <http://dx.doi.org/10.5935/2079-312x.20170019> [02/11/2018].

Ortega, J. de (1512). Conpusición de la arte de la Arismética y de Geometría. León de Francia, Maistro Nicolau de Benedictis (por Joannes Trinxer). [consultado en Mancho y Quirós (2005)]

Pharies, D. (2002). Diccionario etimológico de los sufijos españoles. Madrid: Gredos.

Puche Lorenzo, M. Á. (2019). El léxico de la minería: un puente entre España y América. En C. Garriga, M. L. Pascual y M. B. Pedraza, Lengua de la ciencia y lenguaje de especialidad. Anexos de la Revista de Lexicografía, 42. La Coruña: Servicio de Publicaciones de la Universidad de La Coruña, pp. 283300.

Real Academia Española (2014). Diccionario de la lengua española. Madrid: Espasa Calpe, 23 $3^{\mathrm{a}}$ ed. (DLE). [en línea] <http://dle.rae.es> [02/11/2018]

Real Academia Española (2019). Corpus diacrónico del español. (CORDE). [en línea] $<$ http://corpus.rae.es/cordenet.html> [16/03/2019] 
Rojas, C. de (1598). Teórica y práctica de fortificación. Madrid: Luis Sánchez. [consultado en Mancho y Quirós (2005)]

Sánchez Gómez, J. (2017). De la nada a la cúspide. La minería en el siglo XVI hispano. En A. M. Bernal (Ed.), Modernidad de España: apertura europea e integración atlántica. Madrid: Marcial Pons, pp. 553564. 